\title{
An Analysis of the Fillers Used by Asian Students in Busan, South Korea: A Comparative Study
}

\author{
Valantino Ateng Pamolango
}

\begin{abstract}
The aim of this paper is to emphasize the importance of fillers to students at the university, and investigate how many fillers are used by the students when they answer questions in English and if so, which function of fillers they tend to use and why. Although there might be no teaching issue for acquisition of fillers, being spoken discourse markers, the aim is rather to increase the learners' awareness of fillers when they hesitate in the foreign language, which is actually the very nature of speaking. Ten questions were asked to the students at Dong Eui University in the winter semester of 2016/2017 academic year. The questions were starterd from the easy to the difficult one. 8 students who are using English as their communication tool were chosen from 8 countries in Asia, such as Indonesia, India, Vietnam, Laos, Korea, Philippines, Japan and China. Through voice recordings and related transcriptions, the results basically revealed that the students used fillers in order to answer the hard questions. The data showed that all the students produced more unlexicalized than the lexicalized fillers. In the function of the fillers, the types of fillers produced had the functions as a holder the turn, as a mark of hesitation, as a empathizer, as a time-creating device, and as an editing term. As a conclusion, the more difficult the language used, the more fillers are produced.
\end{abstract}

Index Terms-Fillers, speaking, Asian, international students.

\section{INTRODUCTION}

\section{A. Background of the Study}

The focus of this research is the use of fillers in order to answer questions using English which produced by 8 Asian students at Dong Eui University, Busan, South Korea. A brief observation shows that there are a lot of fillers being used, for example, uh, umm, oh, you know, well, etc. There are 10 (ten) questions in English, start with the easy to the difficult one. The students come from China, India, Indonesia, Japan, Laos, Philippines, South of Korea, and Vietnam in the winter semester of 2016/2017 academic year. However, the researcher only wants to observe the fillers, which are common or appear in asnwering the questions. The reason is because the feature of people's speech, such as pitch, vocabulary, pronunciation, and grammar, vary not only at different gender, but also at different ages (Holmes, 1992) [1].

In spoken interaction, people often produce ee..., err..., ehm..., or well, you know, I mean, kind of, and similar expressions. According to Baalen (2001:7) [2], these kinds of utterances are called fillers. He defines fillers as sounds

Manuscript received March 17, 2016; revised September 12, 2016

Valantino Ateng Pamolango is with the Dong-Eui University, Busan, South Korea and University of 17 Agustus 1945 Surabaya, Indonesia (email: v.a.pamolango@untag-sby.ac.id). or words or phrases that could appear anywhere in the utterance and that could be deleted from the utterance without a change in content. On the other simple words, Yule (2006:242) [3] defines fillers as a break in the flow of speech. Most people produce fillers in their spoken interaction. Here are some examples:

1) A: "What do you do to enjoy your free time? I mean on the weekend."

B: "Umm, You know I don't have much free time although at the weekend. Actually, I want to go to vacation."

\section{B. Objective of the Study}

This research aims to answer the following questions:

1. What are the types and the frequencies of the fillers used by the Asian students?

2. What are the functions of the fillers used by the Asian students?

\section{THEORY}

\section{A. Discourse Analysis}

Discourse analysis is a primarily a branch of linguistic study examining the use of language by its native population whose major concern is investigating language functions along with its forms, produced both orally and in writing. Moreover, identification of linguistic qualities of various genres, vital for their recognition and interpretation, together with cultural and social aspects that support its comprehension, is the domain of discourse analysis. To put it in another way, the branch of applied linguistics dealing with the examination of discourse attempts to find patterns in communicative products as well as and their correlation with the circumstances in which they occur, which are not explainable at the grammatical level (Carter, 1993:23) [4].

\section{B. Fillers in Spoken Discourse}

According to Stenström (1994:222) [5], a filler is lexically an empty item with uncertain discourse functions, except to fill a conversational gap. It means that filler commonly occurs to mark hesitation or to hold control of a conversation while the speaker thinks what to say next. In the next explanation, the writer would present about the kinds of fillers and the frequencies of the fillers used by Asian students.

Fillers in spoken interaction can be divided into two types (Rose, 1998) [6]. The first type is lexicalized fillers. Lexicalized fillers are fillers in the form of short phrases, such as sort of, you know, if you see what I mean, etc. Moreover, one type of fillers, which is similar to the lexicalized fillers, is verbal fillers consist of well, I mean, 
sort of [5]. Furthermore, one of the scholars [2] mentioned that one type of the fillers is like (when it is not used as verb or preposition) and well (not in the initial position). The researcher summarized the kinds of fillers in spoken interaction into three kinds of fillers, they are non-words fillers, such as em, hmm, uh, um, etc; phrase fillers such as $I$ mean, well, sort of, etc; and silent pauses. However, in this study the researcher will discuss about non-words fillers and phrase fillers.

\section{Methodology}

This chapter discussed the details of some steps that the researher used in performing the analysis. The steps discussed in this chapter are the research design, data collection, and data analysis.

The study will be conducted by using descriptive qualitative approach since it intended to analyze more on words than numbers and the findings of this research were reported in the form of statement as Bogdan and Biklen (1982:28) [7] say that the written word is very important in qualitative research to record data and disseminate the findings.

The instrument of this research was the reseacher himself in order to get valid data about the types of the fillers and also the frequencies of the fillers. He managed all things in this research, choosing the subjects, choosing the way of collecting data, and analyzing the data.

As the source of data, the researcher recorded the 8 (eight) Asia students utterances when they answer questions in natural setting. The researcher did an analysis based on the utterances of the subjects. Moreover, the recording process occurred various about $30-60$ minutes, it means the reseacrher only record once for each person. He took the data from the 8 Asian students. The recording was taking for 8 days, which means one student for one day. Then, the data would be the utterances from the 8 Asian students which contained fillers. After getting the data, the writer listened the recorded conversation once again in order to get accurate data. After that, he transcribed the utterances. Then, the he jotted it down word by word and put the utterances in a form of line. After that, he identified the fillers and numbered the utterances lines containing fillers. Next, the researcher would italicized and bolded the fillers that occurred in the lines of the utterances. The researcher then analysed the utterances which contain lexicalixed dan unlexicalixed fillers, after that, put them into their types and functions.

\section{DISCUSSION}

The Table I shows that the Asian students used two types of fillers, which are lexicalized and unlexicalized fillers. The types of fillers used the most frequently by the Asian students were unlexicalized fillers with the number of occurrences 332 , then lexicalized fillers with the number of occurrences 80 . From the total number of each type of fillers, the most popular fillers were $\boldsymbol{e} \boldsymbol{e}-\{\partial: m\}$, followed by ya $\{y e s\}$ in the second position. Then, fillers repetitive words in the third position.

TABLE I: THE TyPeS OF FILLERS USED By THE MALE LECTURERS

\begin{tabular}{|c|c|c|c|c|c|c|}
\hline \multirow[b]{3}{*}{ No } & \multirow[b]{3}{*}{ Origin } & \multicolumn{4}{|c|}{ Types of Fillers } & \multirow{3}{*}{$\begin{array}{c}\begin{array}{c}\text { Number of } \\
\text { Frequency }\end{array} \\
\mathbf{n}\end{array}$} \\
\hline & & \multicolumn{3}{|c|}{ Unlexicalized } & \multirow{2}{*}{$\begin{array}{c}\text { Lexicalized } \\
\text { Repetitive words }\end{array}$} & \\
\hline & & $e e-\{a: m\}$ & ya $\{y e s\}$ & ok & & \\
\hline 1. & China & 23 & 13 & 3 & 8 & 47 \\
\hline 2. & India & 18 & 19 & 7 & 7 & 51 \\
\hline 3. & Indonesia & 25 & 12 & 5 & 7 & 42 \\
\hline 4. & Japan & 17 & 13 & 4 & 9 & 43 \\
\hline 5. & Laos & 28 & 15 & 6 & 14 & 49 \\
\hline 6. & Philippines & 24 & 16 & 6 & 12 & 58 \\
\hline 7. & South of Korea & 19 & 13 & 4 & 12 & 48 \\
\hline 8. & Vietnam & 24 & 14 & 4 & 11 & 53 \\
\hline \multirow{2}{*}{\multicolumn{2}{|c|}{ TOTAL }} & 178 & 115 & 39 & \multirow{2}{*}{80} & \multirow{2}{*}{412} \\
\hline & & \multicolumn{3}{|c|}{332} & & \\
\hline
\end{tabular}

In details, from the table above, it can be seen that the fillers $\boldsymbol{e} \boldsymbol{e}-\{a: m\}$ with the number of occurrences 178 was the type of unlexicalized fillers used the most frequently by the Asian students. The filler as $\boldsymbol{y} \boldsymbol{a}\{\boldsymbol{y} \boldsymbol{e s}\}$ with the number of occurrences 115 in the second position. Then, filler repetitive words with the number of occurrences 80 in the third position. After that, the fillers $\boldsymbol{o} \boldsymbol{k}$ with the number of occurrences 39. Here, the researcher would explain further about each type of the unlexicalized fillers and give example for each of it.

\section{A. The Types of Unlexicalized Fillers Used by the Asian Students}

The types of Unlexicalized filler produced by the Asian students $\boldsymbol{e} \boldsymbol{e}-\{a: m\}, y \boldsymbol{a}$ (yes) and $\boldsymbol{o k}$. In the following parts, the writer would give examples from each type of the unlexicalized fillers.

\section{I have ee-ee been here once}

ee-I love the weather

pardon? passion yes ok- good passion yeah I think so, what else? (sentence 3)

yes. yes.. I think the people here is very friendly . But, they can not speak English and I can not speak Korean well too. (sentence 27)

ok. Korean food is a bit difference from my country's food. But, it is ok for me, because i have no option ok. (sentence 36)

It is different with Indonesian - ya- (yes) it is different 
with Indonesian, we eat rendang - ya- (yes) using spoon even using a natural hand (Sentence 39)

salah-saya gak tanya yang itu, keliru - they always look fashion ya- (yes) every day, they make up and dress very well ya- (yes) I don't want to be like them by using so many make-up (Sentence 62)

If you eat - ee- what they call-ee- if you eat ee- what a barbeque for the example, what do you use? (Sentence 64)

\section{B. The Types of Lexicalized Fillers Used by the Asian Students}

The types of Lexicalized fillers produced by the Asian students in answering questions in English were repetitive words that functioned as the fillers. Here the researcher would explain further about each type of the lexicalized fillers and give example for each of it.

like it's ee-more value - more value yes-so this is like last week - last week you - last week we discuss aboutKorean language (Sentence 12)

like I said before it's ee-more friendly - more friendly. uhm this is what $i$ like from them - from them - The professors help me a lot during - during the class (Sentence 16)

I think it is not good-good what they call-culture it's not new experience- disciplines experience- it is - it isdevelops from time to time from the language what they call- what they call- new ideology (Sentence 41)

there are many ideas, there are many information that I ee- have to be record as be ee-what you said-as be the speaker so you have to listen very carefully, there is the first (Sentence 59)

What is call as ee-poet, poetry - in ee- in the previous ee-in the old ( ) who who can produce ee-a worst with a ( ) multiplying ee-the matter, multiplying the diction and ee- a playing the, the regulation or the conversion in producing a good poems. The professor is good in making ee-ee-poet. (Sentence 71)

So there is ee-what they call-ee-kind of a regulation in which you have to eat a steak made of a meat - with ee-what ee- what tools you have to cut the meat? Ya- (yes) of course you we we we ee-there is ee-what they call-a knife (Sentence 77)

Actually, which plan must be divined as a culture, in the previous times the-culture is ee-divined from the top - from the elite, from the ee- what they call- a mainstream scholars - and then it is ee- what they callthe culture is ee-followed by the society (Sentence 79)

An example, for example - there is a handsome - man with a lot of money, very generous, very generous have three husbands eh- sorry three wifes - a formal three wife - what do you think? Is it good or bad? It is good- but the man is still spent the money for another woman that is not his wife (Sentence 104)

But not just ordinary family they are not ordinary family, what family? - rich royal family yes - royal family how, how they - how they hide their guilty - they always want to hide their guilty - they always want to hide their mistake - they have a big mistake they have a big sin but they always want to hide their sin - itu simbolnya orang kerajaan, they always want try to hide their sin-mereka punya dosa but they always want to hide, menyembunyikan dosa (Sentence 111)

\section{The Function of Fillers Used by the Asian Students}

In this research, the researcher presents and discusses five functions of the fillers in the spoken interaction [5], that is, fillers function as a holder the turn, as a mark of hesitation, empathizers, time-creating devices, and editing term. In the production of fillers by the Asian students, it was shown that the Asian students tended to produce more fillers as mark of hesitation. Those fillers were followed by fillers as time-creating devices and fillers that functioned as editing term. The other two functions, those are, fillers are functioned as editing term empathizer and holder the turn. They were using all of these functions in answering the 10 (ten) questions.

In the transcribing data of the 8 Asian students' utterances, based on the theory about the function of fillers, the reseacher found that the fillers could be defined in five functions [5]. The highest position on the functions of fillers produced by those students were, fillers as a mark of hesitation with percentage $(38,4 \%)$. Then, the second- fillers produced by them functioned as a empathizer (37\%), the fillers functioned as time-creating devices in the third position $(19,9 \%)$, the fillers functioned as an editing term in the fourth with percentage $(3,3 \%)$, and the last fillers as holder the turn $(1,4 \%)$.

\section{CONCLUSION}

In this research, the researcher observed the types and the functions of fillers produced by the Asian students in Busan, South of Korea. The researcher found that all of the Asian students used fillers in order to answer the English questions. Student from Philippines produced the highest number of fillers, with the number of occurrences 58 . The second one is Vietnam, with the number of occurrences 53. Followed by India, with the number of occurrences 51 . Next is Laos, with the number of occurrences 49. South of Korea produced 48 fillers. After that, China number 6 (six), with the number of occurrences 47 . Japan produced 43 fillers. The smaller number of fillers produced by Indonesia, with the number of occurrences 42. Then, all the Asian students produced the unlexicalized fillers $e e-\{\partial: m\}, y a(y e s)$, and $o k$. Then, The data shows that all those students produced more unlexicalized fillers 332 fillers than lexicalized fillers with the number of occurrences 80 fillers. After that, all the Asian students used those 5 functions of fillers, for example as a holder the turn, as a mark of hesitation, as a empathizer, as a time-creating device, and as an editing term. 
As a conclusion, not only the students from Asia produced more fillers, but also the foreign students who use English for the first language. Moreover, the more difficult the language we used, the more fillers are produced and fillers are really useful. It helps to make the conversation runs smoothly and look more comfortable.

\section{ACKNOWLEDGMENT}

I would like to express my high gratitude to my supervisor and the Graduate School members at Dong-Eui University, Busan, South Korea who have motivated me in doing some researches. Then, I would like to express my deep gratitude to the University of 17 Agustus 1945 Surabaya, Indonesia who has fully supported me in having a chance to join this conference. Last, it is for my beloved family in Indonesia and the Netherlands who never stop supporting and loving me.

\section{REFERENCES}

[1] J. Holmes, An Introduction to Sociolinguistics, New York: Addison Wesley Longman Publishing, 1992.
[2] I. V. Baalen. (2001). Male and Female Language: Growing Together? [Online]. Available: http://www.let.leidenuniv.nl/hsl_shl/vanBaalen.htm

[3] G. Yule, The Study of Language, Cambridge: CUP, 2006.

[4] R. Carter, Introducing Applied Linguistics, Harlow: Penguin, 1993.

[5] A. Stenström, An Introduction to Spoken Interaction, London: Longman, 1994.

[6] R. L. Rose. (1998). The Communicative Value of Filled Pauses in Spontaneous Speech. [Online]. Available: http://www.roselab. sci.waseda.ac.jp/ resources/file/madissertation.pdf

[7] R. C. Bogdan and S. K. Biklen, Qualitative Research for Education: An Introduction to Theory and Methods, Boston: Allyn and Bacon, Inc., 1982.

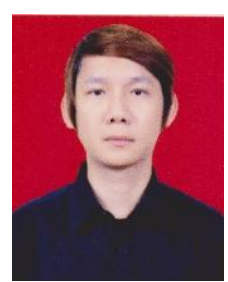

Valantino Ateng Pamolango was born in Luwuk, on March 6, 1987, he is doing his $\mathrm{PhD}$ at Dong Eui University, Busan, South Korea. He took his master at Sam Ratulangi University, Manado majored in theoretical linguistics, 2012. His bachelor degree was taken at Petra Christian University Surabaya majored in English letters, 2009. He teaches at University of 17 Agustus 1945 Surabaya. Furthermore, he is conducting his dissertation research about MorphoSyntaxis of Saluang Language. Besides, he has already presented his researches in some national and international conferences. 